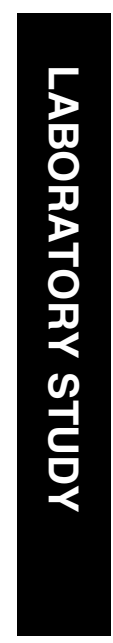

\section{In vivo lamellar keratoplasty using platelet-rich plasma as a bioadhesive}

${ }^{1}$ Ophthalmology

Department, Facultad de Ciencias Biomédicas, Universidad Austral, Pilar, Argentina

${ }^{2}$ Transfusion Department, Hospital Universitario Austral, Universidad Austral, Pilar, Argentina

${ }^{3}$ Ocular Pathology Department, Fundación Oftalmológica Argentina 'Jorge Malbran', Buenos, Argentina

Correspondence: JE Gallo, Ophthalmology

Department,

Universidad Austral, Avenue Peron 1500 Pilar,

Buenos Aires B1629AHJ, Argentina.

Tel: + 0542322482946 ;

Fax: + 054232248 2216;

E-mail: jgallo06@

gmail.com

Received: 30 June 2008 Accepted in revised form: 15 February 2009

Published online: 20 March 2009

Part of this work was presented at the ARVO Annual Meeting and at the AAO Annual Meeting in 2004

\section{Abstract}

Purpose The use of standard sutures has been replaced by platelet-rich plasma (PRP), a bioadhesive agent, in several surgical procedures. This prompted us to test PRP efficacy in experimental lamellar keratoplasty. Methods After lamellar anterior keratoplasty, PRP with a mean concentration of 807564 platelets $/ \mathrm{mm}^{3}$ was used to attach the corneal flap to the stromal surface in 12 New Zealand white rabbits. 10-0 nylon sutures were used in one control group of 12 animals and no suture was used in a second control group of six rabbits. Animals were killed at days 2, 7, 30, and 90 for histological and smooth muscle actin (SMA) immunohistochemical analysis. Results The PRP group showed a tight corneal graft from the first postoperative hours until they were killed. A transparent cornea was seen at 30 days and remained clear until the end of the protocol. Histological specimens showed no signs of ocular inflammation in any animal within the PRP group. Electron microscopy showed normal morphological features on the flap and stromal bed, and a clear interface zone without cells or debris. The number of stromal myofibroblasts was lower than that seen in the suture group at $\mathbf{3}$ months postsurgery. The sutured group showed an attached cornea with signs of inflammation around the knots. All flaps without PRP or sutures were completely detached in the immediate postoperative period.

Conclusions PRP was useful for attaching the corneal flap and it was well tolerated by the rabbit corneal tissue. Corneal healing was satisfactory. Further studies on PRP adhesiveness in grafts with donor corneas should be performed before considering its use in patients.

Eye (2010) 24, 368-375; doi:10.1038/eye.2009.49; published online 20 March 2009
F Luengo Gimeno1, SC Gatto², JO Croxatto³, JI Ferro ${ }^{2}$ and JE Gallo'

Keywords: sutureless; lamellar keratoplasty; corneal transplantation; platelet-rich-plasma

\section{Introduction}

Lamellar keratoplasty (LK) is a surgical procedure used widely. Most surgeons agree on the essential role of the suture technique in achieving a successful outcome. ${ }^{1}$ Well-placed sutures minimise refractive aberrations and inflammatory reactions. Different types of sutures have been the subject of many investigations during the last years.

Nevertheless, sutures are considered risk factors for epithelial erosions, inflammation, suture abscess, infectious keratitis, refractive errors, and graft rejection. ${ }^{2}$

Sutureless surgeries in ophthalmology could provide some benefits to the patient, such as shorter time of surgery, less inflammatory reaction, corneal neovascularisation, and infections. Avoiding sutures may prevent asymmetric healing, which, in turn, results in refractive aberrations. That is why tissue adhesives have been within the scope of several experimental eye studies since the 1960s. ${ }^{3}$ At present, several fibrin adhesives are commercially available. They have been tested for multiple purposes such as treatment of perforated corneal ulcers, either healing the perforation ${ }^{4}$ or preventing infections ${ }^{5}$, and closure of the conjunctiva in strabismus, ${ }^{6}$ pterygium, ${ }^{7}$ and glaucoma surgery. ${ }^{8}$ Many ophthalmologists have employed them in the attachment of scleral homografts ${ }^{9}$ or closure of the scleral tunnel after cataract extraction ${ }^{10}$ and in the stabilisation of radial keratotomy wounds. ${ }^{11}$ Tissue adhesives have also been used as biological sutures in lamellar keratoplasty in humans. ${ }^{12}$ 
The platelet-rich plasma (PRP) is an autologous bioadhesive product that concentrates a high number of platelets in the small volume of plasma. It contains several plasma components, all of which contribute to tissue healing. ${ }^{13}$ The plasma components are the three isomers of platelet-derived growth factors (PDGF1, PDGF2, and PDGF3), two transforming growth factors (TGF1 and TGF2), vascular endothelial growth factor, fibronectin, and epithelial growth factor. ${ }^{14}$ PRP is obtained by the centrifugation of the patient's own blood. It is naturally degraded in 2-3 weeks; its biocompatible and biodegradable properties prevent foreign body reactions, tissue necrosis, or extensive fibrosis. It can be used in very small surgical areas and interfaces because of its easy handling. PRP has an extraordinary strength and it has been used in patients by dentists, ${ }^{15}$ oral maxillofacial surgeons, ${ }^{16}$ plastic surgeons, ${ }^{17}$

cardiovascular surgeons, ${ }^{18}$ and otorhinolaryngologists. ${ }^{19}$ Recently, ophthalmological publications refer to PRP used in dry eye treatment ${ }^{20}$ and corneal ulcers healing. ${ }^{21}$

To the best of our knowledge, autologous PRP has not yet been used in LK. We aimed at examining the clinical evolution of the adhesive flap as well as the interaction between PRP and corneal tissue in rabbits.

\section{Materials and methods}

Thirty New Zealand white male rabbits weighing $3000 \mathrm{~g}$ on average (2500-3500 g) were included in our study. Animals were treated according to the ARVO Statement for the Use of Animals in Ophthalmic and Vision Research.

\section{Preparation of platelet-rich plasma}

The animals were anaesthetised using intramuscular midazolam $(0.2 \mathrm{mg} / \mathrm{kg})$ and ketamine $(0.3 \mathrm{mg} / \mathrm{kg})$. Preparation of PRP was done according to the method described earlier. ${ }^{22}$ Briefly, PRP containing $\sim 800000$ platelets was prepared for activation by calcium chloride $\left(\mathrm{CaCl}_{2}\right)$, which inhibits the anticoagulation effect of anticoagulant citrate dextrose (ACD) on blood. After activation, the PRP was quickly transformed into a gellike solution with adhesive properties and ready for use. This activated gel-like PRP, with coagulating properties, remained in this state for about $15 \mathrm{~min}$.

\section{Surgical technique}

PRP and 10-0 nylon sutures were used in 12 rabbits, respectively (PRP group and sutured group), whereas neither PRP nor sutures were utilised in six control animals in which the corneal button was gently placed over the stroma (non-PRP and non-sutured group).

\section{PRP group: LK using PRP}

Lamellar anterior keratectomy, using a $6 \mathrm{~mm}$-diameter trephine, was performed on right eyes under a ZEISS S5-Pro operating microscope (Zeiss C, Overckochen, Germany). The corneal button was excised according to Malbran's peeling off technique. ${ }^{23}$ The flap was then soaked in autologous plasma for about $3 \mathrm{~min}$. In the meantime, PRP was activated, transformed into a gel and placed over the stromal surface. The corneal flap was finally replaced on the stroma. Corneal graft adherence was manually verified at the end of the procedure with the aid of a delicate forceps.

\section{Sutured group: LK with 10-0 nylon sutures}

Once the corneal button was excised by the same surgical technique, it was irrigated with $\mathrm{BSS}(0.9 \% \mathrm{NaCl})$ for $1 \mathrm{~min}$ and placed again on the stromal surface. The corneal button was sutured with eight interrupted 10-0 nylon sutures. Suture knots were rotated and buried into the recipient stroma.

\section{Non PRP/Non-sutures group LK without using adhesives or sutures}

Lamellar anterior keratectomy was performed, the corneal button was irrigated with BBS as above and it was left on the stromal surface without using sutures or PRP.

\section{Postoperative management and follow-up}

A partial tarsorraphy using three 5-0 silk sutures was carried out, closing two-thirds of the palpebral fissure. Topical $0.3 \%$ ciprofloxacin and $0.1 \%$ dexamethasone drops were applied four times daily for 21 days. The partial tarsorraphy was removed on day 2. Clinical follow-up examinations were performed daily during the first week and weekly thereafter using an operating microscope under general anaesthesia. Examinations were carried out with special attention to corneal adhesiveness, inflammatory reaction, and clarity. We manually tested the adhesiveness with the use of a delicate forceps at each control day. These features were photographically documented using a Nikon Coolpix 5700 Digital Camera (Nikon, Tokyo, Japan) on days 2, 7, 30 , and 90 .

\section{Histology}

Three animals in each group were killed at day 2, 1 week, 1 month, and 3 months after surgery. The eyeball was enucleated and placed in $10 \%$ paraformaldehyde. The cornea was extracted from the globe using delicate forceps and scissors, and cut into three vertical pieces, two for light microscopic examination and one for 
electron microscopy. Histological specimens were stained with hematoxylin and eosin, periodic acid-Shiff stain and Masson trichrome stain, and examined with a Nikon Eclipse E800 microscope (Nikon, Tokyo, Japan).

\section{Electron microscopy}

Samples for electron microscopy were fixed in $3.2 \%$ glutaraldehyde buffered $\mathrm{pH} 7.4$ at $4^{\circ} \mathrm{C}$ overnight and postfixed in $1 \%$ osmium tetroxide, dehydrated and embedded in resin (Der Resin, Polysciences Inc., Warrington, PA, USA). Thin sections $(60 \mathrm{~nm})$ were stained with uranyl acetate and lead citrate, and observed with an EM-109 Electron Microscope (Carl Zeiss, Overckochen, Germany). ${ }^{24}$

\section{Immunohistochemistry and immunofluorescense}

Primary antibodies against smooth muscle actin (SMA) were used to identify the presence of myofibroblasts in the corneal stroma of animals in the sutured group and PRP group, at days 7, 30, and 90 postoperatively. Two normal untreated rabbits underwent the same immunohistochemical analysis for comparison.

Corneal samples were cut at $10 \mu \mathrm{m}$ thickness in a cryostat and processed for the diaminobenzidine (DAB) and immunofluorescence (IF) techniques. Sections were incubated with monoclonal mouse antiserum to SMA $1: 500$ overnight (Sigma-Aldrich, St Louis, MO, USA), $\sim 12 \mathrm{~h}$. For DAB, the sections were then incubated with biotinylated goat anti mouse IgG for $1 \mathrm{~h}(1: 100)$ (Vector, CA, USA) followed by avidin-biotin-peroxidase for $1 \mathrm{~h}$ (ADP) (Vectastain, Vector, CA, USA), and showed with
DAB enhanced by ammonium nickel sulfate. For IF technique, goat anti mouse fluorescent serum for $30 \mathrm{~min}$ (1:40) (Jackson Immune Research Laboratories, PA, USA) was used and sections were finally rinsed and mounted in a mixture of glycerol and PBS $(3: 1)$ containing para-phenylenediamine. ${ }^{25}$

\section{Count of stromal SMA (+) cells}

Cell counts were performed following the method described by Andreoni et al. ${ }^{26}$ Image analysis measurements were obtained using a KS400 system (Kontron Elektronic/Zeiss, Zeiss C, Overckochen, Germany) and a Hyper HAD Sony CCD IRIS black and white video camera mounted onto an Optiphot-2 Nikon microscope for image acquisition. Six immunolabeled area values, each of 47730 pixels, ${ }^{2}$ were randomly selected per cornea sample. At least three samples per cornea were used. Images were digitalised in a rectangular frame of $640 \times 480$ pixels using the $10 \times$ objective in the photo mode of illumination intensity. To adjust possible defects in the illumination of optical pathway, a low-pass image was produced for subtraction and background shading correction. After that, a grey value for image segmentation was interactively chosen. After defining a threshold grey level, all the pixels whose grey value informative content was lower or higher than the segmentation grey were set to white, and the others were set to black. With the Kontron system, the black elements were counted and the mean value was calculated for stromal SMA $(+)$ cells in each sample tested. Statistical analysis was performed using Student $t$-test (Table 1).

Table 1 Corneal grafts - summary of clinical and immunohistological findings

\begin{tabular}{|c|c|c|c|c|c|c|c|c|}
\hline & \multicolumn{2}{|c|}{2 days } & \multicolumn{2}{|c|}{7 days } & \multicolumn{2}{|c|}{30 days } & \multicolumn{2}{|c|}{90 days } \\
\hline & $P R P$ & $S$ & $P R P$ & $S$ & $P R P$ & $S$ & $P R P$ & $S$ \\
\hline \multicolumn{9}{|l|}{ Clinical findings } \\
\hline Opacity & +++ & ++ & ++ & + & - & - & - & - \\
\hline Epithelial defects & - & + & - & - & - & - & - & - \\
\hline Neovascularisation & - & - & - & + & - & ++ & - & ++ \\
\hline Adhesive flap & ++ & +++ & +++ & +++ & +++ & +++ & +++ & +++ \\
\hline \multicolumn{9}{|l|}{ Histological findings } \\
\hline Stratified epithelium & ++ & +++ & +++ & +++ & +++ & +++ & +++ & +++ \\
\hline Inflammatory cells & - & ++ & - & +++ & - & + & - & + \\
\hline Endothelial abnormalities & - & - & - & - & - & - & - & - \\
\hline Regular architecture of lamellas & +++ & ++ & +++ & + & +++ & ++ & +++ & ++ \\
\hline Adhesive flap & + & +++ & + & +++ & +++ & +++ & +++ & +++ \\
\hline \multicolumn{9}{|l|}{ Immunohistochemical findings } \\
\hline SMA & + & + & ++ & ++ & + & +++ & - & +++ \\
\hline
\end{tabular}



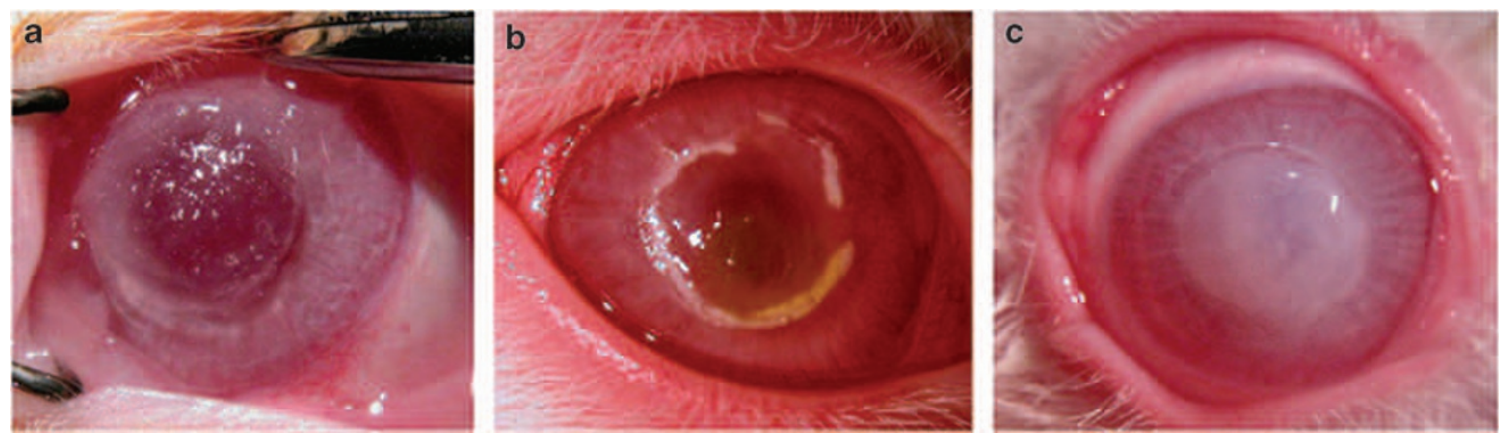

Figure 1 Clinical evolution of PRP during the immediate postoperative hours. The activated PRP is instilled between the stroma and the flap (a). An opalescent peripheral halo of coagulated PRP is seen $10 \mathrm{~min}$ after instillation (b). Platelet coagulation gives the cornea a whitish appearance $6 \mathrm{~h}$ after instillation (c).

We certify that all applicable institutional and governmental regulations regarding the ethical use of animals were followed during this research.

\section{Results}

In the immediate postoperative period, the implanted corneal button had a transient opalescent halo followed by a whitish appearance because of the glue and cornea oedema (Figure 1). The opacity cleared slowly for several days and a clear cornea was seen at 30 days and remained transparent until the end of the protocol in all animals with PRP (Figure 2).

The animals in groups $\mathrm{P}$ and $\mathrm{S}$ showed a tightly attached corneal graft from the first postoperative hours until they were killed. Both groups showed corneal oedema but the whitish appearance was not present in the $\mathrm{S}$ group. Animals in group $\mathrm{N}$ showed a complete corneal button detachment at day 2 after removal of the tarsorraphy.

Histological specimens showed no signs of inflammation in group P. The corneal epithelium was slightly thin at day 2. Its morphology began to normalise from day 7 onwards. Remnants of PRP were found on day 7 , but they were not seen on day 30 or later (Figure 2k). Cellular infiltrates around the nylon knots were seen in the sutured group, whereas an erratic healing with a big inflammatory reaction and detached corneal flap was seen in the second control group. Electron microscopy showed normal morphological features of the flap, stromal bed, and a clear interface zone free of cells or debris in group $\mathrm{P}$, whereas group $\mathrm{S}$ showed expected lamellar disorganisation and the presence of leucocytes (Figure 3).

The number of stromal myofibroblasts (SMA + cells) was similar between groups P (1117 cells/FdaArea/ Pixel2) and S (1242 cells/FdaArea/Pixel2) 1 week after surgery. A significant higher number of cells were found in group S at 90 days postsurgery (2502 cells/FdaArea/ Pixel2). A similar number of myofibroblasts was seen in the normal (without any surgery) and PRP corneas 90 days after transplantation (75, 75 and 81,75 cells/ FdaArea/Pixel2) (Figures $3 \mathrm{c}$ and $\mathrm{d}$ and 4 ).

\section{Discussion}

Clinical and histological findings showed corneal flap adhesiveness in all rabbits. PRP was well tolerated by the corneal tissue. There were no signs of toxicity. Corneal wound healing progressed satisfactorily in the PRP group and a normal evolution was seen in sutured group. Corneal clarity and lack of inflammation were achieved in all grafts 90 days postsurgery.

Platelet-rich plasma is an autologous substance with a high number of platelets and several plasma components that contribute to tissue adhesiveness and healing. ${ }^{14}$ Besides, PRP as an autologous substance is assimilated in the immune system without causing rejection. PRP preparation in humans is well established. ${ }^{17}$ However, PRP preparation in rabbits is rather more difficult because of the reduced blood sample that can be extracted. ${ }^{22}$ The volume of blood is critical because too much extraction can be lethal to the animal. It is necessary to reach a balance between animal survival and quantity of blood needed to make PRP.

It is important to consider how PRP degradation occurred in the corneal tissue. A manifest opacity resulting from the coagulation of platelets was still present in the corneal flap 2 days after surgery. From the third day onwards the opacity began to diminish, and an almost clear cornea was clinically observed after 1 week. This trend continued, and a crystal clear cornea was seen at 1 and 3 months. The histological findings correlated with the clinical appearance. After 1 month, the stromalcorneal interface zone was verified as platelet debris-free by electron microscopy. 

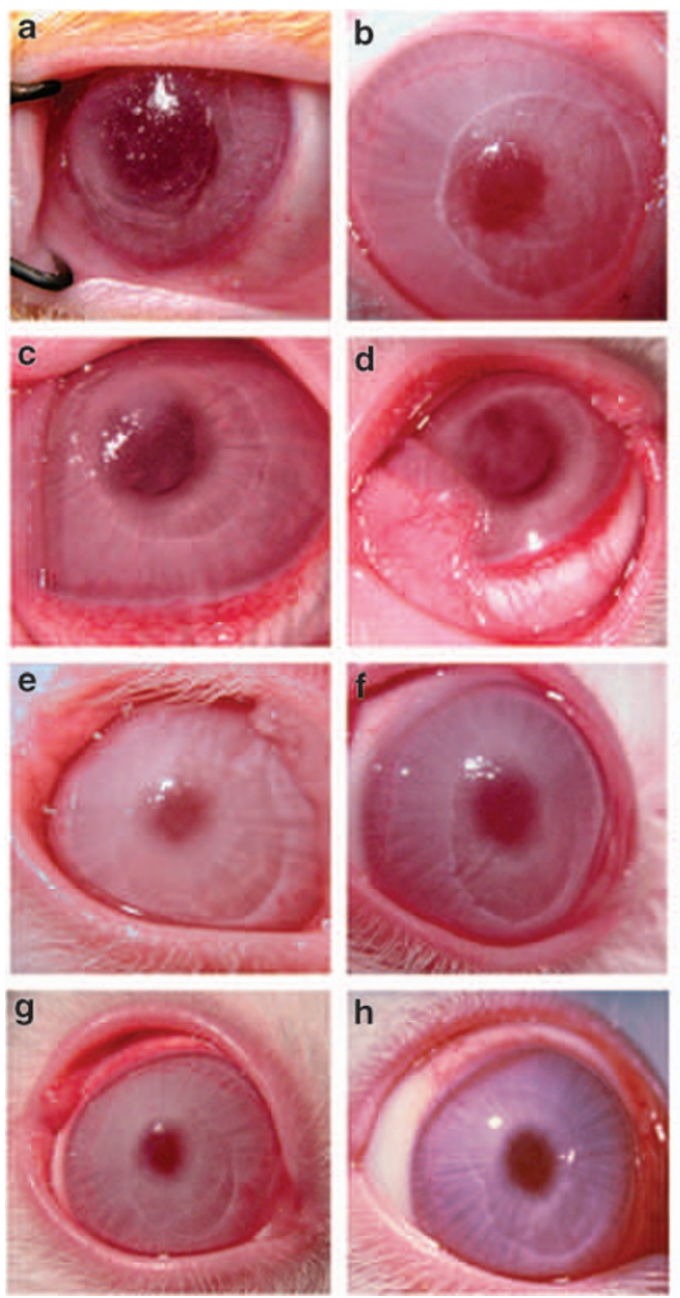
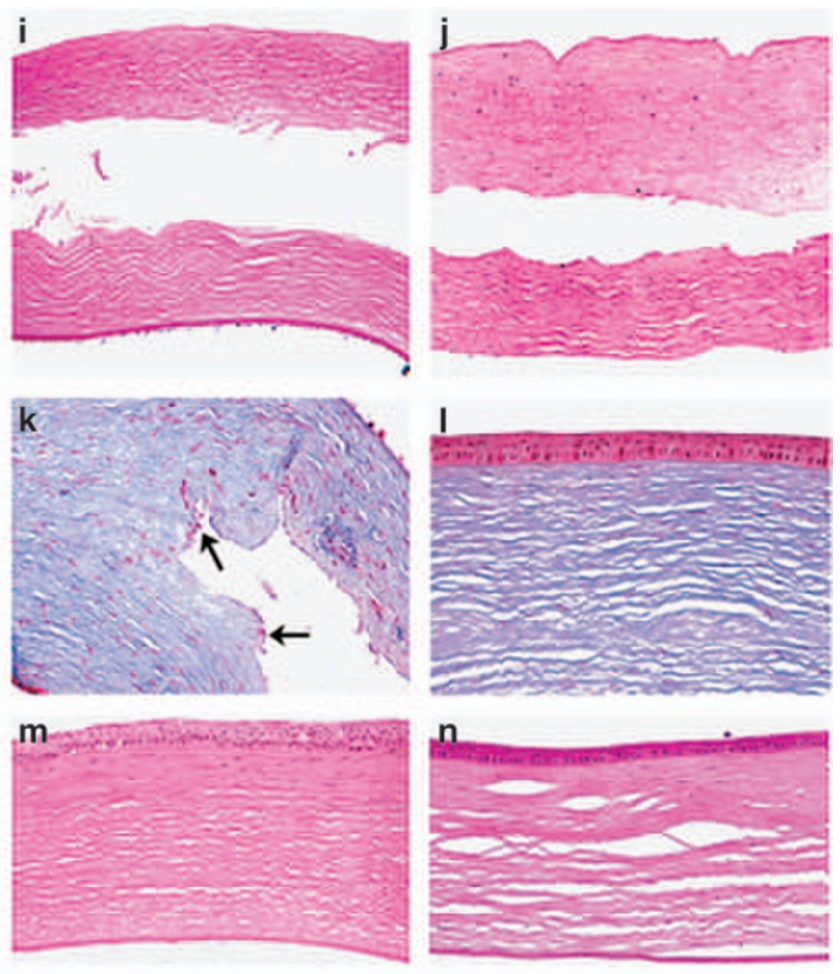

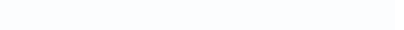

Figure 2 Corneal postoperative photographs in group P (a-h) at days 2, 7, 30, and 90 and histopathology of the cornea in group $\mathrm{P}(\mathrm{i}, \mathrm{k}, \mathrm{m})$ and $\mathrm{S}(\mathrm{j}, \mathrm{l}, \mathrm{n})$, at days 2, 7, and 90.(a and b) two different corneal flaps at day 2 showed a cloudy interface. (c) and (d): a mild opacity is seen at day 7 , which progressed to a substantial clearness manifested at 30 (e and f) and 90 days (g and h). (i and j) detached interfaces are seen at day 2 because of tissue retraction after processing (PAS, $60 \times$ and H\&E stain, $60 \times$, respectively).(k) granular deposits of coagulated PRP are present till day 7 (arrows) (see clinical appearance in Figure 3C) (Masson's trichrome stain, $125 \times$ ). $(\mathrm{m}$ ) attached lamellar flap is seen 90 days after surgery (H\&E stain, $125 \times)$. ( $($ and $n)$ in the suture group the flaps are attached without inflammation of the corneal stroma at 1 week (Masson's trichrome stain, $125 \times$ ) and 90 days (H\&E stain, $125 \times$ ), respectively.

The process of apoptosis of stromal myofibroblasts is considered a key factor to achieve suitable wound healing. ${ }^{27}$ This plays a major role in corneal transparency development. ${ }^{28}$ In our study, the fact that myofibroblast counts 90 days after transplantation were similar between PRP corneas and normal corneas, higher than in sutured corneas, suggests that PRP does not interfere the process of cellular apoptosis in corneal wound healing. Further studies are necessary to confirm this observation.

Grafted allogenic tissues may cause immunogenic reactions to the cornea. ${ }^{29}$ By using the rabbits' own corneal button and PRP (autologous method) we ruled out a possible host versus graft response, which might have influenced the interaction between PRP and corneal tissue.

Some reports have recently pointed out that PRP may prevent infections because of the joint presence of platelets and white blood cell, as well as promoting a faster wound healing process. ${ }^{13,30}$ This may help to avoid infections after lamellar keratoplasty. Some contributing factors to tissue healing are known to facilitate the development of angiogenesis; however, no signs of neovascularisation were found in PRP grafts. ${ }^{14}$

The strength of PRP adhesiveness was reported to be satisfactory in non-ophthalmic surgical investigations. ${ }^{15-19}$ In our study, the clinically and histologically successful outcomes constituted signs of 

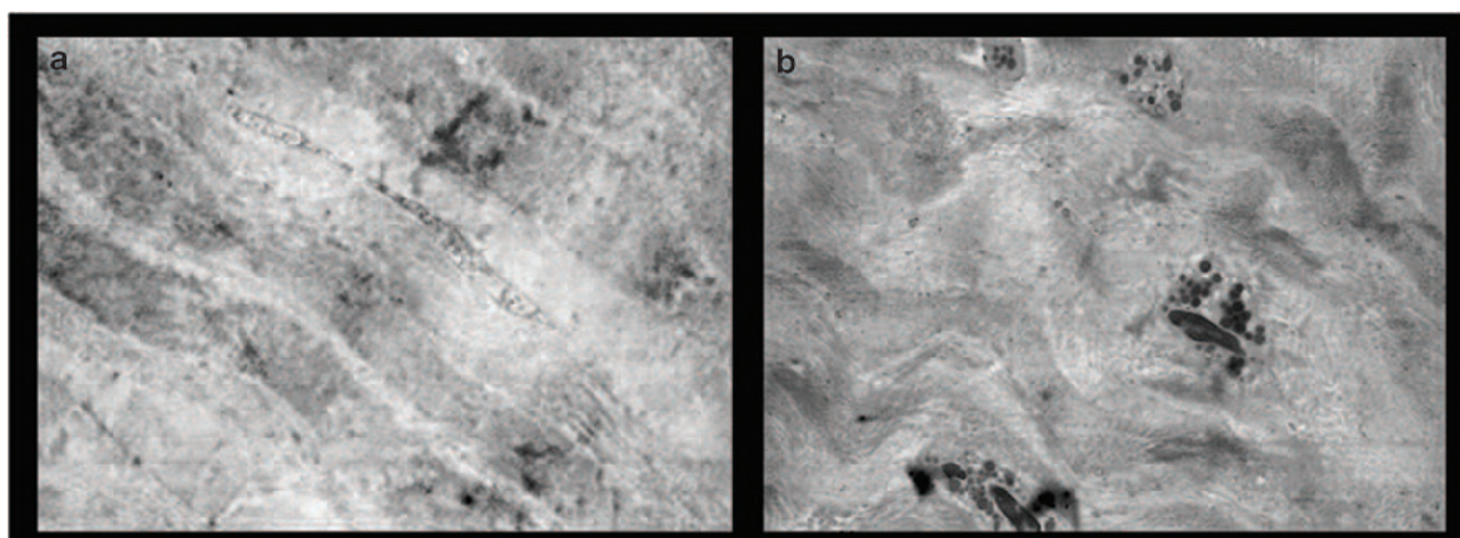

c
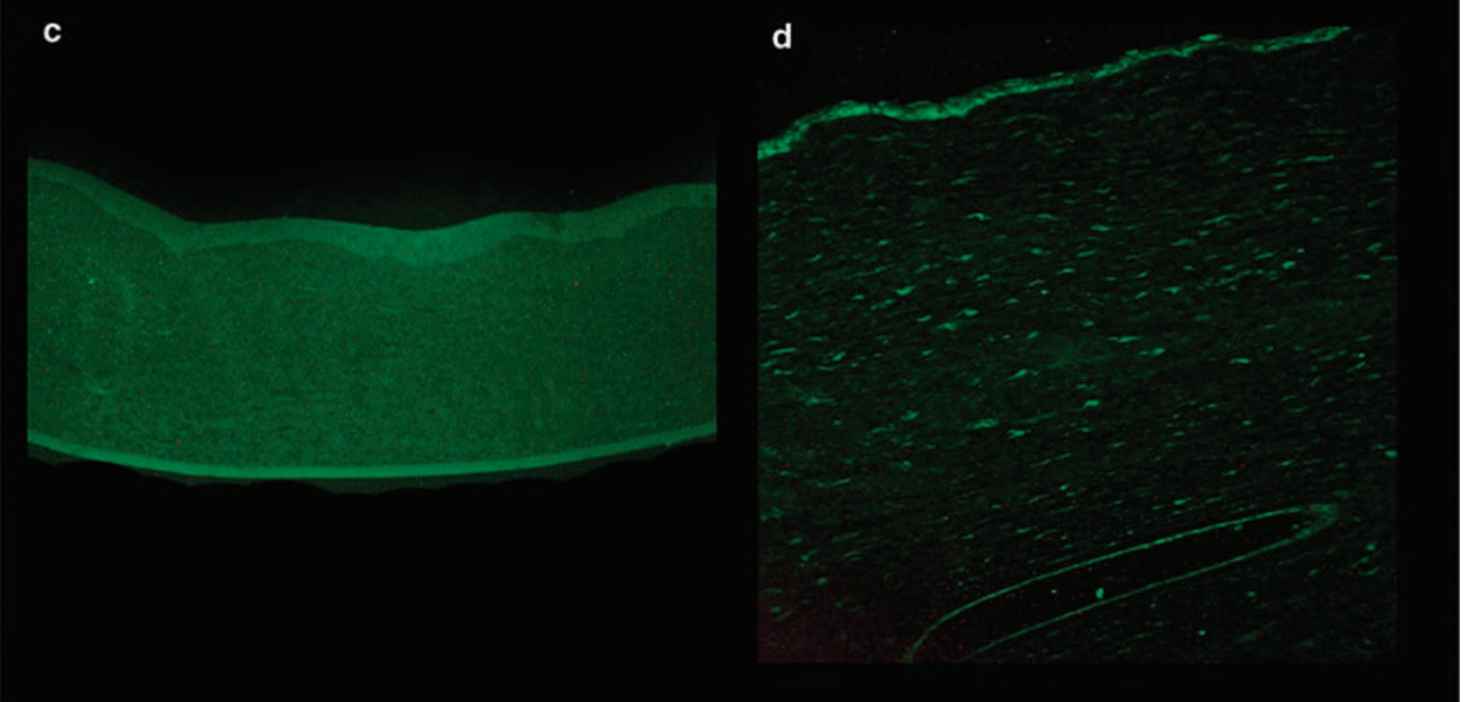

Figure 3 Electron microscopy of corneal stroma in group P (a) and group S (b) and corneal SMA immunofluorescence in group P (c) and S (d) 90 days postsurgery. (a) Regular arrangement of collagen forming stromal lamellas and normal morphology of keratocytes. (b) Stromal disarray of collagen lamellas and inflammatory cells presumably representing leucocytes near the suture knots. (c): no corneal SMA fluorescence is seen in group P. (d) Group S shows corneal SMA fluorescence mainly around nylon sutures.

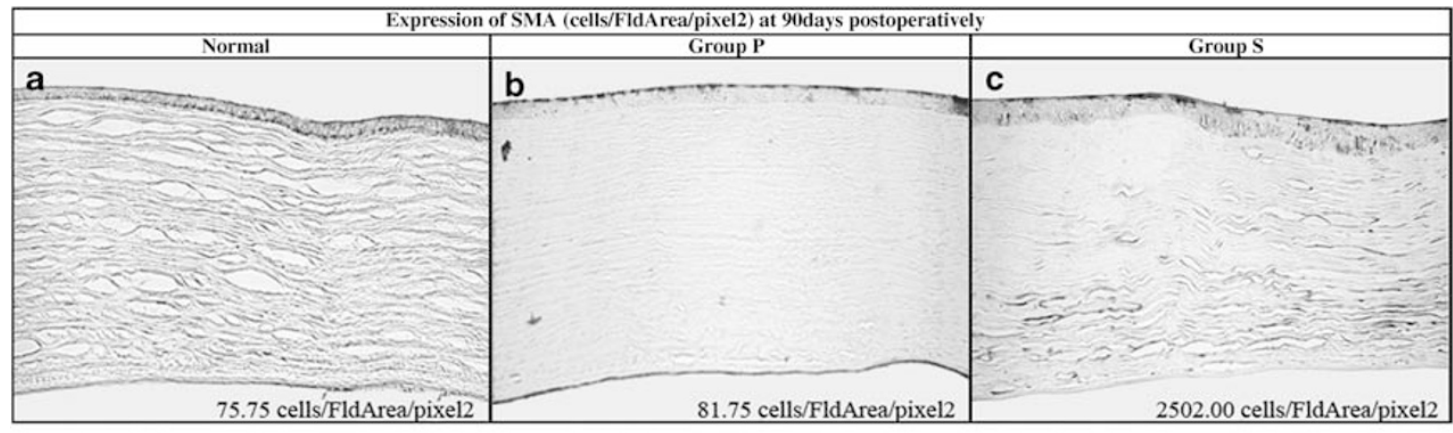

\begin{tabular}{l|r|r|r}
\multicolumn{4}{c}{ Comparative expression of SMA (cells/fdaArea/pixel2) } \\
\hline & 7 days & \multicolumn{1}{c}{30 days } & 90 days \\
\hline Group N (normal) & 75.75 & 75.75 & 75.75 \\
Group P (PRP) & 1117.92 & 509.38 & 81.75 \\
Group S (sutures) & 1242.00 & 1800.00 & 2502.00
\end{tabular}

Figure 4 Image analysis of SMA immunostaining in the stroma of untreated corneas (a) and treated corneas in group P and S 90 days postsurgery. ( $a$ and b) SMA immunostaining in group $\mathrm{P}$ is similar to that found on a normal cornea (c) an evident difference is seen in group $\mathrm{S}$. The measurements were made by quantitative densitometry and the data are shown as the mean \pm SEM. 
PRP suitable adhesiveness in lamellar keratoplasty in a rabbit model. We did not use a quantitative method with objective measurements. It was subjectively quantitated. Nevertheless, we are aware of the importance of measuring the adhesive power of PRP for attaching the corneal flap, which will be done in a future investigation.

At present, LASIK flaps are left on the corneal stroma without sutures. They become attached after several hours. In our study, the flaps made are deeper taking one-third of the stroma in comparison to one-fifth of LASIK's flaps (laser-assisted in situ keratomileusis). This could account for the detached corneal flaps in all rabbits in which no adhesives or sutures had been used. Anyway, the main difference between LASIK flap and the corneal buttons is the hinge, which does not exist in free grafts. In addition, different behaviour between humans and rabbits also may play a role.In summary, PRP is an inexpensive, easily-handled bioadhesive and a pro-healing, autologous product that is well tolerated by the animal's own cornea as it was shown earlier in our study. ${ }^{31}$ PRP could be also useful in pterygium surgery and in modern corneal surgery using the femtosecond laser. New studies are being conducted at our own laboratory to elucidate PRP usefulness in LK.

\section{Acknowledgements}

This work was supported by grants from Pan-American Association of Ophthalmology and Austral University. We are grateful to Germán Ruffolo, Guillermo Gastón, Isabel Farias, and Nora Torry for their skilful technical assistance.

\section{References}

1 Terry MA. The evolution of lamellar grafting techniques over twenty-five years. Cornea 2000; 19: 611-616.

2 Christo CG, van Rooij J, Geerards AJM. Suture-related complications following keratoplasty: a 5-year retrospective study. Cornea 2001; 20: 816-819.

3 Webster Jr RG, Slansky HH, Refojo MF, Boruchoff SA, Dohlman $\mathrm{CH}$. The use of adhesive for the closure of corneal perforations. Arch Ophthalmol 1968; 80: 705-709.

4 Sharma A, Kaur R, Kumar S, Gupta P, Pandav S, Patnaik B et al. Fibrin glue versus N-butyl-2-cyanoacrylate in corneal perforations. Ophthalmology 2003; 110: 291-298.

5 Eiferman RA, Snyder JW. Antibacterial effect of cyanoacrylate glue. Arch Ophthalmol 1983; 101: 958-960.

6 Spierer A, Barequet I, Rosner M. Reattachment of extraocular muscles using fibrin glue in a rabbit model. Invest Ophthalmol Vis Sci 1996; 38: 543-546.

7 Koranyi G, Seregard S, Kopp ED. Cut and paste: a no suture, small incision approach to pterygium surgery. $\mathrm{Br} \mathrm{J}$ Ophthalmol 2004; 88: 911-914.

8 O'Sullivan F, Dalton R, Rostron CK. Fibrin glue: an alternative method of wound closure in glaucoma surgery. J Glaucoma 1996; 5: 367-370.
9 Lee KH, Kim MS, Hahn TW, Kim JH. Comparison of histological findings in wound healing of rabbit scleral homografts with fibrin glue (Tisseel ${ }^{\mathrm{R}}$ ) and suture material. J Refract Surg 1995; 11: 397-401.

10 Kim JC, Bassage SD, Kempski MH, del Cerro M, Park SB, Aquavella JV et al. Evaluation of tissue adhesives in closure of scleral tunnel incisions. J Cataract Refract Surg 1995; 21: 320-325.

11 Goins KM, Khadem J, Majmudar PA, Ernest JT. Photodynamic biologic tissue glue to enhance corneal wound healing after radial keratotomy. J Cataract Refract Surg 1997; 23: 1331-1338.

12 Kaufman HE, Insler MS, Ibrahim-Elzembely HA, Kaufman SC. Human fibrin tissue adhesive for sutureless lamellar keratoplasty and scleral patch adhesion. Ophthalmology 2003; 110: 2168-2172.

13 Eppley BL, Woodell JE, Higgins J. Platelet quantification and growth factor analysis from platelet-rich plasma: implications for wound healing. Plast Reconstr Surg 2004; 114: $1502-1508$.

14 El-Sharkawy H, Kantarci A, Deady J, Hasturk H, Liu H, Alshahat $\mathrm{M}$ et al. Platelet-rich plasma: growth factors and pro- and anti-inflammatory properties. J. Periodontol 2007; 78: 661-669.

15 Carlson NE, Roach Jr RB. Platelet-rich plasma: clinical applications in dentistry. J Am Dent Assoc 2002; 133: 1383-1386.

16 Grageda E. Platelet-rich plasma and bone graft materials: a review and a standardized research protocol. Implant Dent 2004; 13: 301-309.

17 Man D, Plosker H, Winland-Brown JE. The use of autologous platelet-rich plasma (platelet gel) and autologous platelet-poor plasma (fibrin glue) in cosmetic surgery. Plast Reconstr Surg 2001; 107: 229-237.

18 Christenson JT, Kalangos A. Autologous fibrin glue reinforced by platelets in surgery of ascending aorta. Thorac Cardiovasc Surg 2004; 52: 225-229.

19 Silberstein LE, Williams LJ, Hughlett MA, Magee DA, Weisman R. An autologous fibrinogen-based adhesive for use in otologic surgery. Transfusion 1988; 28: 319-321.

20 Alio JL, Colecha JR, Pastor S, Rodriguez A, Artola A. Symptomatic dry eye treatment with autologous plateletrich plasma. Ophthalmic Res 2007; 39: 124-129.

21 Alio JL, Abad M, Artola A, Rodriguez-Prats JL, Pastor S, Ruiz-Colecha J. Use of autologous platelet-rich plasma in the treatment of dormant corneal ulcers. Ophthalmology 2007; 114: 1286-1293.

22 Luengo Gimeno F, Gatto S, Ferro J, Croxatto JO, Gallo JE. Preparation of platelet-rich plasma as a tissue adhesive for experimental transplantation in rabbits. Thromb J 2006; 4: 18.

23 Polack FM. Lamellar keratoplasty, Malbran's peeling off technique. Arch Ophthalmol 1971; 86: 293-295.

24 Hayat MA. Basic Techniques for Transmission Electron Microscopy 1986.

25 Coons AH. Fluorescent antibody methods. In:Danielli JF (eds) General Cytochemical Methods. Academic Press: New York, 1958 pp 399-422.

26 Andreoni G, Angeretti N, Lucca E, Forloni G. Densitometric quantification of neuronal viability by computerized image analysis. Exp Neurol 1997; 148: 281-287.

27 Wilson SE. Analysis of the keratocyte apoptosis, keratocyte proliferation, and myofibroblast transformation responses after photorefractive keratectomy and laser in situ 
keratomileusis. Trans Am Ophthalmol Soc 2002; 100: 411-433.

28 Wilson SE, Netto M, Ambrosio Jr R. Corneal cells: chatty in development, homeostasis, wound healing, and disease. Am J Ophthalmol 2003; 136: 530-536.

29 Stark W, Taylor H, Stark WJ, Taylor HR, Bias WB, Maumenee AE. Histocompatibility (HLA) antigens and keratoplasty. Am J Ophthalmol 1978; 86: 595-604.
30 Trowbridge CC, Stammers AH, Woods E, Yen BR, Klayman M, Gilbert C. Use of platelet gel and its effects on infection in cardiac surgery. J Extra Corpor Technol 2005; 37: 381-386.

31 Alio JL, Abad M, Artola A, Rodriguez-Prats JL, Pastor S, Ruiz-Colecha J. Use of autologous platelet-rich plasma in the treatment of dormant corneal ulcers. Ophthalmology 2007; 114: 1286-1293. 